\title{
Rescuing the NIH before it is too late
}

In the Coen brothers' The Big Lebowski the hero, who calls himself "The Dude," has just had his apartment broken into by some dumb thugs. One of the thugs lifts the Dude's prized bowling ball and says, "What ... is this?" The Dude replies, "Obviously you are not a golfer." The current state of the NIH prompts me to say to its director, Dr. Elias Zerhouni, "Obviously you are not a scientist.”

Dr. Zerhouni's apparent lack of understanding of how science is done is compounded by the utter lack of support for biomedical science from the White House and Congress. Neither Democrats nor Republicans appear to understand the key role of science in the nation's health, welfare, and economy. The White House under George W. Bush is targeting the NIH for destruction.

The NIH has been a national treasure for over 50 years, supporting the world's best and most productive scientific enterprise. To allow the current cutbacks in NIH support (after the doubling of the NIH budget under the Clinton administration) is akin to doubling the number of teams in major league baseball, then cutting their budgets so that one-third of the players are out of jobs. The net effect on our nation's scientific productivity is devastating and will be for years to come, as much of the progress that the NIH budget doubling funded will now be wasted.

Particularly hard hit are junior investigators. Certainly they must feel like they are trying to hit a bowling ball with a golf club. Many of the ideas that Dr. Zerhouni has proposed in his Roadmap seem practical and even forward thinking. However, the use of the term road map to describe Dr. Zerhouni's new directions for the NIH is misleading: a road map is a document that helps its readers locate their present locations, plot a course to a new location, and relocate once they arrive. The NIH Roadmap is not a road map at all, but a yellow brick road: it looks like it will lead us back to Kansas, but the way is really fraught with danger, the end of the road is not really where we want to go, and it is all just a fantasy. It was irresponsible of Dr. Zerhouni to use scarce funds to support his new initiative before protecting the most tried and true mechanism for funding science: the investigator-initiated RO1 grant. Instead, precious resources that the nation's scientists depend on for survival have been diverted to support a new enterprise whose success, directions, and goals are vague and unproven.

Equally frustrating are the hundreds of millions of dollars being wasted on poorly designed clinical studies whose results are suspect, yet splashed all over the lay press. A case in point is the recent study

\section{Continued misdirection \\ and neglect of the NIH will have long-lasting disastrous consequences for biomedical research.}

proclaiming that high-fat diets do not increase the risk of disease (1). No doubt this study, which cost the taxpayers over $\$ 400$ million (funds that could have supported 400 scientists for 5 years each) was designed by a committee of well-intentioned experts. I can only speculate that the study design was a masterpiece of compromise that ended up doomed to failure and, worse, has set back progress in the area of improving the nation's health. In any case, the NIH should not fund large clinical studies that divert hundreds of millions of dollars away from hypothesisdriven scientific research; pharmaceutical companies should. The fear that this will take control away from clinical investigators is a false diversion because all human studies must be approved by institutional review boards, which could readily impose the ethical, moral, and academic standards of the most rigorous clinical investigators.

There are achievable solutions that can reverse the demise of the NIH and rescue one of our nation's most precious resources. First, members of Congress need to step forward and champion the cause of supporting biomedical research. The NIH budget should be restored, with appropriate annual increases. This is an easy sell to the electorate, as every citizen has a vested interest in the development of cures for diseases and technologies that can improve the efficiency and reduce the cost of delivering health care. Second, the Roadmap needs to be shelved and the funds restored to the pool of resources that support investigator-initiated individual RO1 grants. Third, large clinical studies that suck up hundreds of millions of dollars need to be supported by pharmaceutical companies that are eager to fund them. Fourth, the process for funding established investigators needs to be streamlined and focused on productivity rather than on false promises. Some scientists are receiving millions of dollars of precious NIH funding and have little to show for it. Established investigators applying for competitive renewals should be required to provide a brief progress report and outline of proposed new directions along with their top 3-5 papers published in the previous funding period. The study sections could then make renewal contingent on the productivity and impact of the previously funded period, by far the best indicator of future success.

With these four simple steps we can ensure the health of our national scientific research enterprise and rescue the NIH before it is too late. The NIH is an essential component of the scientific community, one that we have grown comfortable with and somewhat taken for granted. Continued misdirection and neglect of the NIH will have long-lasting disastrous consequences for biomedical research and our ability to achieve scientific breakthroughs that can reduce human suffering and save lives.

\section{Andrew R. Marks Editor-in-chief}

1. Howard, B.V., et al. 2006. Low-fat dietary pattern and risk of cardiovascular disease: the Women's Health Initiative Randomized Controlled Dietary Modification Trial. JAMA. 295:655-666. 